\title{
OPEN Meta-analysis on how manure application changes soil organic carbon storage
}

\begin{abstract}
Arthur Gross \& Bruno Glaser ${ }^{\bowtie}$
Manure application to agricultural soils is widely considered as a source of nutrients and a method of maintaining levels of soil organic carbon (SOC) to mitigate climate change. At present, it is still unclear which factors are responsible for the SOC stock dynamics. Therefore, we analyzed the relationship between SOC stock changes and site characteristics, soil properties, experiment characteristics and manure characteristics. Overall, we included 101 studies with a total of 592 treatments. On average, the application of manure on agricultural soils increased SOC stocks by $35.4 \%$, corresponding to $10.7 \mathrm{Mg} \mathrm{ha}^{-1}$. Manure applications in conventional tillage systems led to higher SOC stocks $\left(+2.2 \mathrm{Mg} \mathrm{ha}^{-1}\right)$ than applications under reduced tillage. Soil organic carbon increase upon manure application was higher in soils under non-tropical climate conditions (+ $2.7 \mathrm{Mg} \mathrm{ha}^{-1}$ ) compared to soils under sub-tropical climate. Larger SOC increases after manure application were achieved in intermediate and shallow topsoils (in 0-15 cm by $9.5 \mathrm{Mg} \mathrm{ha}^{-1}$ and in $16-20 \mathrm{~cm}$ by $13.6 \mathrm{Mg} \mathrm{ha}^{-1}$ ), but SOC stocks were also increased in deeper soils ( $\left.>20 \mathrm{~cm} 4.6 \mathrm{Mg} \mathrm{ha}^{-1}\right)$, regardless of the tillage intensity. The highest relative SOC increase (+48\%) was achieved if the initial SOC was below $1 \%$ but the absolute SOC increased with increasing initial SOC. Clay soils showed higher SOC increase rates compared to sandy soils $\left(+3.1 \mathrm{Mg} \mathrm{ha}^{-1}\right)$. Acidic soils showed comparable relative effects but a higher stock difference than neutral ( $\left.+5.1 \mathrm{Mg} \mathrm{ha}^{-1}\right)$ and alkaline soils (+5.1 $\left.\mathrm{Mg} \mathrm{ha}^{-1}\right)$. The application of farmyard-, cattle- and pig manure showed the highest SOC increases $(50 \%, 32 \%$ and $41 \%$, respectively), while green manure and straw showed only minor effects. If manure applications were combined with additional mineral fertilizer, the SOC increases were higher $\left(+1.7 \mathrm{Mg} \mathrm{ha}^{-1}\right)$ compared to manure alone. Higher applied amounts generally led to higher SOC stocks. However the annually applied amount is only important under conventional tillage, non-tropical climate conditions, and $\mathrm{pH}$-neutral as well as SOC-rich or SOC-depleted soils and if no additional mineral fertilization is applied. Further studies should focus on the SOC dynamics under tropical climate conditions and factors influencing a potential carbon saturation. In both cases, the number of data was too small. For this reason, additional field studies should be conducted primarily in the tropics. On the other hand, long-term field trials should be re-assessed or newly established to specifically investigate potential saturation effects and long-term ( $>20$ years) fertilizer effects and carbon sequestration.
\end{abstract}

The continuously rising concentrations of atmospheric greenhouse gases (GHG) due to human and natural emissions are the main drivers of climate change ${ }^{1}$. This necessitates approaches for mitigating GHG emissions. Strengthening renewable energies or mitigating emissions using carbon capture and storage (CCS) or carbon capture and use (CCU), are possible GHG mitigation options ${ }^{2}$. However, since the switch to renewable energy supplies is still limited by political and market barriers, and geological storage technologies such as CCS are associated with certain risks ${ }^{3}$, they have less acceptance ${ }^{4}$. Nonetheless, there remains a need for sustainable and safe carbon removal from the atmosphere.

Soils are an important carbon sink, as they contain more carbon than stored in terrestrial vegetation and the atmosphere combined ${ }^{5}$. Several regional studies showed that there is still potential to store even more carbon in soils, if certain management practices are applied ${ }^{6,7}$. This process of storing organic carbon in soils, better known as carbon sequestration, describes how organic carbon is put into soils and converted into a stabilized form in the long-term (> 100 years). Besides its beneficial climatic effects, higher soil organic carbon (SOC) content promotes several important soil functions, such as nutrient transformation and supply, soil-water balance control 
or buffering of pollutants ${ }^{8}$. In short, soil organic matter (SOM) is important for adapting to climate change as well as mitigating it.

Theoretically, there are many ways of increasing the SOC pool ${ }^{9}$. However, most of their practical potential is limited. For instance, while no tillage did not significantly increase SOC stocks ${ }^{10}$, cover crops increased SOC stock by $9-10 \%$, based on a review of global meta-analysis data ${ }^{11}$. Another option is to use different organic materials with high carbon content as soil amendments. Manure is a collective term for excrements of different animal species, urine, plant materials and straw but also livestock feed residues and human household waste. Manure nitrogen production increased from 21.4 $\mathrm{Tg} \mathrm{N}_{\text {year }}{ }^{-1}$ in 1860 to $131.0 \mathrm{Tg} \mathrm{N}_{\text {year }}{ }^{-1}$ in 2014 with an annual increasing trend of $0.7 \mathrm{Tg} \mathrm{N}_{\text {year }}{ }^{-1}{ }^{12}$. Cattle dominated the manure nitrogen production and contributed $\sim 44 \%$ of the total manure nitrogen production in 2014 , followed by goats, sheep, swine, and chicken ${ }^{12}$. The manure nitrogen application to cropland accounts for less than one-fifth of the total manure nitrogen production ${ }^{12}$. Manure might also increase carbon in soils as these materials have high carbon content. However, organic matter in manure might also be easily degraded due to its high nitrogen content or its low carbon-to-nitrogen ratio. Many individual studies measured the impact of manure application on SOC stocks, with few studies showing increases in SOC stocks, but also studies showing only small or even negative impacts. Due to this wide variation in results, there is a need for studies clarifying factors that control the magnitude of change in SOC stocks due to manure application. Up to now, only two quantitative reviews have tried to find global relationships between the magnitude in SOC stock changes and different explanatory factors. Han et al. ${ }^{13}$ focused on combined treatments of manure and mineral fertilizer and Maillard and Angers ${ }^{14}$ included studies with mineral fertilizer as reference to manure treatments. Furthermore, Maillard and Angers ${ }^{14}$ only considered articles published up to 2011.

Due to this current lack of clear evidence and statistically significant relationships between SOC stock changes upon manure application and global explanatory factors, we conducted a meta-analysis. The aim of this study was to calculate the response ratio of carbon stocks to manure application and the SOC stock difference under consideration from data available from peer-reviewed studies (ISI Web of Science). Furthermore, our target was to identify clear evidence of influencing factors. For this purpose, we grouped and analyzed the results according to the following criteria: site characteristics (climate zone), soil properties (initial SOC content, $\mathrm{pH}$ value, soil texture), experiment characteristics (tillage intensity, experiment duration, sampling depth) and manure characteristics (manure type, added manure amount, additional mineral NPK fertilizer). In addition to the analysis within individual categories, we also examined intercategorical effects to investigate possible interactions between the investigated factors.

\section{Material and methods}

Data sources, collection and categorization. In order to analyze SOC stock changes following manure application, a meta-analysis was conducted. Within this framework, we performed a systematic literature review using "ISI Web of Science (Core Database)". The search term was "(Soil organic matter OR C Sequestration) AND Manure". Studies were included if they were performed under field conditions and if the effect and control size was expressed as content of total organic carbon (TOC) or quantified as SOC or TOC stocks. If SOM rather than SOC information were given in a study, we calculated SOC as SOM multiplied by 0.58 . All treatments with a duration of $\leq 3$ years were removed to exclude short-term effects and the influence of the cultivated crops. Overall, 101 studies with a total of 592 treatments were included.

Besides information on SOC content, we also extracted information on soil properties (initial SOC content, texture, bulk density, soil $\mathrm{pH}$ class), experiment characteristics (tillage intensity, duration, sampling depth), manure characteristics (type, added amount, additional mineral fertilizer use) and site characteristics (longitude, latitude, altitude, climate zone). To limit the variety of different soil texture classes, we decided to group them into their respective dominant particle size class (sand, silt or clay). Exceptions are the middle classes "clay loam and loam". These have been added to "loam". If data were only presented in figures, WebPlotDigitizer Version 4.2 was used for the extraction of data. In order to analyze the total amount of manure added, annual amounts were accumulated.

If no information on SOC stocks was provided, we quantified them using the following Eq. $(1)^{15}$,

$$
\text { SOC stock }=\text { SOC } \times \text { Bulk density } \times \text { Depth } \times 0.1
$$

where SOC stock is expressed as $\mathrm{Mg} \mathrm{ha}^{-1}$, bulk density as $\mathrm{g} \mathrm{cm}^{-3}$, depth as $\mathrm{cm}$ and SOC as $\mathrm{g} \mathrm{kg}^{-1}$. In a few studies, no soil bulk density was given. In these cases, we used different pedotransfer functions. If studies included information on the initial SOC, silt and clay content, we used the pedotransfer function given in Men et al. ${ }^{16}$ (Eq. 2). If studies included information on the initial SOC and the clay content, we used an equation given in Bernoux et al. ${ }^{17}$ (Eq. 3). If studies only provided information on initial SOC, we used a pedotransfer function given in Manrique and Jones ${ }^{18}$ (Eq. 4).

$$
\begin{gathered}
\text { Bulk density }=1.386-0.078 \times \text { SOC }+0.001 \times \text { Silt }+0.001 \times \text { Clay } \\
\text { Bulk density }=1.398-0.0047 \times \text { Clay }-0.042 \times \text { SOC } \\
\text { Bulk density }=1.660-0.318 \times S O C^{0.5}
\end{gathered}
$$

where bulk density is expressed as $\mathrm{g} \mathrm{cm}^{-3}$ and the SOC, silt and clay content as \%. To better understand the factors influencing SOC stock changes, we grouped the study results as follows: tillage intensity type, climate zone, initial SOC, soil texture, sampling depth, soil $\mathrm{pH}$ class, added annual manure amount, cumulative manure amount, manure type, additional mineral fertilizer and experiment duration. 
Data analysis. To estimate the effects of manure applications on SOC stock changes, we used two different indices. We calculated the response ratio $(\mathrm{R})$, which is the mean of the manure treatment divided by the mean of the control group (all the same but without manure application) and we calculated the SOC stock mean difference $(\triangle S O C)$. To measure experimental effect sizes, $\mathrm{R}$ and $\Delta \mathrm{SOC}$ are both very common and wide-spread in meta-analyse ${ }^{13,14,19-21}$. It is essential to calculate both indices as $\mathrm{R}$ only gives information on relative changes whereas $\triangle \mathrm{SOC}$ considers the absolute impact. The consideration of only one of those indices can be misleading. Two similar absolute SOC changes can be the result of either a low or a high relative SOC change, depending on the initial SOC content.

$\mathrm{R}$ was calculated using the following equation:

$$
R=\left(\frac{X_{E}}{X_{C}}\right)-1
$$

where $\mathrm{X}_{\mathrm{E}}$ is the mean SOC stock with manure application and $\mathrm{X}_{\mathrm{C}}$ is the mean SOC stock without application of manure (control group) for each treatment. In order to better interpret the result, 1 was subtracted from each $\mathrm{R}$ value.

More precise meta-analysis are using a weighting according to the number of repetitions, the standard deviation or the standard error. Considering the fact that only a few of the analyzed studies provided sufficient information on statistical measures and replicates, we decided to use un-weighted meta-analysis, to include as many treatments as possible. "Un-weighted" meta-analysis is a commonly used approach, which gives all included studies the same weight, e.g. a weight of $1^{13,22-24}$. SOC stock differences were calculated by using Eq. (6):

$$
\triangle S O C=X_{E}-X_{C}
$$

where $\mathrm{X}_{\mathrm{E}}$ represents the mean SOC stock in $\mathrm{Mg} \mathrm{ha}^{-1}$ of the experimental group and $\mathrm{X}_{\mathrm{C}}$ the mean SOC stock in $\mathrm{Mg} \mathrm{ha}^{-1}$ of the control group.

For reasons of better interpretation, 95\% confidence intervals (CI) were calculated as follows:

$$
\begin{aligned}
& C I \text { upper }=\text { Ror } \triangle S O C \frac{+1.96 * \sigma}{\sqrt{n}} \\
& C I \text { lower }=\text { Ror } \triangle S O C \frac{-1.96 * \sigma}{\sqrt{n}}
\end{aligned}
$$

with the mean response ratio $\mathrm{R}$ or the SOC stock mean difference $\Delta \mathrm{SOC}$ in $\mathrm{Mg} \mathrm{ha}^{-1}, 1.96$ the confidence coefficient, $\sigma$ the standard deviation and $\mathrm{n}$ the number of individual treatments.

All of these statistical measures are presented as forest plots. Visualisation was conducted with R Version 3.5.2 $2^{25}$. The overall grand mean of all individual treatments is presented in the first row. The grey solid line represents an $\mathrm{R}$, or a mean difference equal to 0 , thus no effect. An effect size larger than 0 indicates a positive effect (i.e. an increase of SOC upon manure application), and lower than 0 a negative effect (i.e. a decrease of SOC upon manure application). Each effect size is presented as the range between the upper and lower $95 \%$ confidence interval. The line inside of both confidence intervals represents the range of the effect size. The range between both confidence intervals of the grand mean is shown by the extent of the rectangle. If the effect size range crosses the "zero-effect-line", the result can be interpreted as statistically insignificant. The mean effect sizes of each group were considered to be significantly different at $p<0.05$ from each other if the $95 \%$ confidence intervals were not-overlapping. The number after the name of the examined category represents the number of included treatments.

In the inter-categorical evaluation, all influencing factors were compared with each other. Due to the resulting large number of data, we decided to examine only those intermediate category treatments that occurred at $\mathrm{n} \geq 10$. Furthermore, we eliminated all treatments in the intercategorical evaluation, which applied combinations of manure types due to too many different combinations and, therefore, too few repetitions per manure treatment class.

To analyze the connection of $\triangle S O C$ and added manure amounts under the influence of various factors, a linear regression analysis was conducted using R Version 3.5.2 ${ }^{25}$. We calculated the coefficient of determination $\mathrm{R}^{2}$ and the statistical connection was determined by using the Pearson correlation coefficient $\mathrm{R}$. Normal distribution was checked using the Shapiro-Wilk test.

\section{Results and discussion}

General effect. Overall, 101 studies with a total of 592 treatments were analyzed in this study (Supplementary Dataset 1). All of them were conducted under field conditions. No laboratory experiments were included. Locations in North America $(n=8)$, South America $(n=2)$, Sub-Saharan Africa $(n=5)$, Europe $(n=11)$, West Africa $(n=2)$, South Asia $(n=20)$ and East Asia $(n=53)$ were included. The results of all subcategories, including their standard deviation can be found in the Supplementary Dataset 2. The results of the intercategorical grouping is located in the Supplementary Dataset 3 and their corresponding forest plots can be found in the Supplementary Material.

As expected, the results obtained from 592 pairwise comparisons showed a significant increase of SOC stocks of $35 \%$ (95\% CI 32-39\%) and a $\Delta$ SOC of $10.7 \mathrm{Mg} \mathrm{ha}^{-1}$ (95\% CI 9.8-11.6 Mg ha ${ }^{-1}$ ) on average, after manure was applied despite high variation among different groups. This positive effect can mainly be explained by the fact that manure applications are direct inputs of carbon into soil and a source of nutrients (especially nitrogen), which 


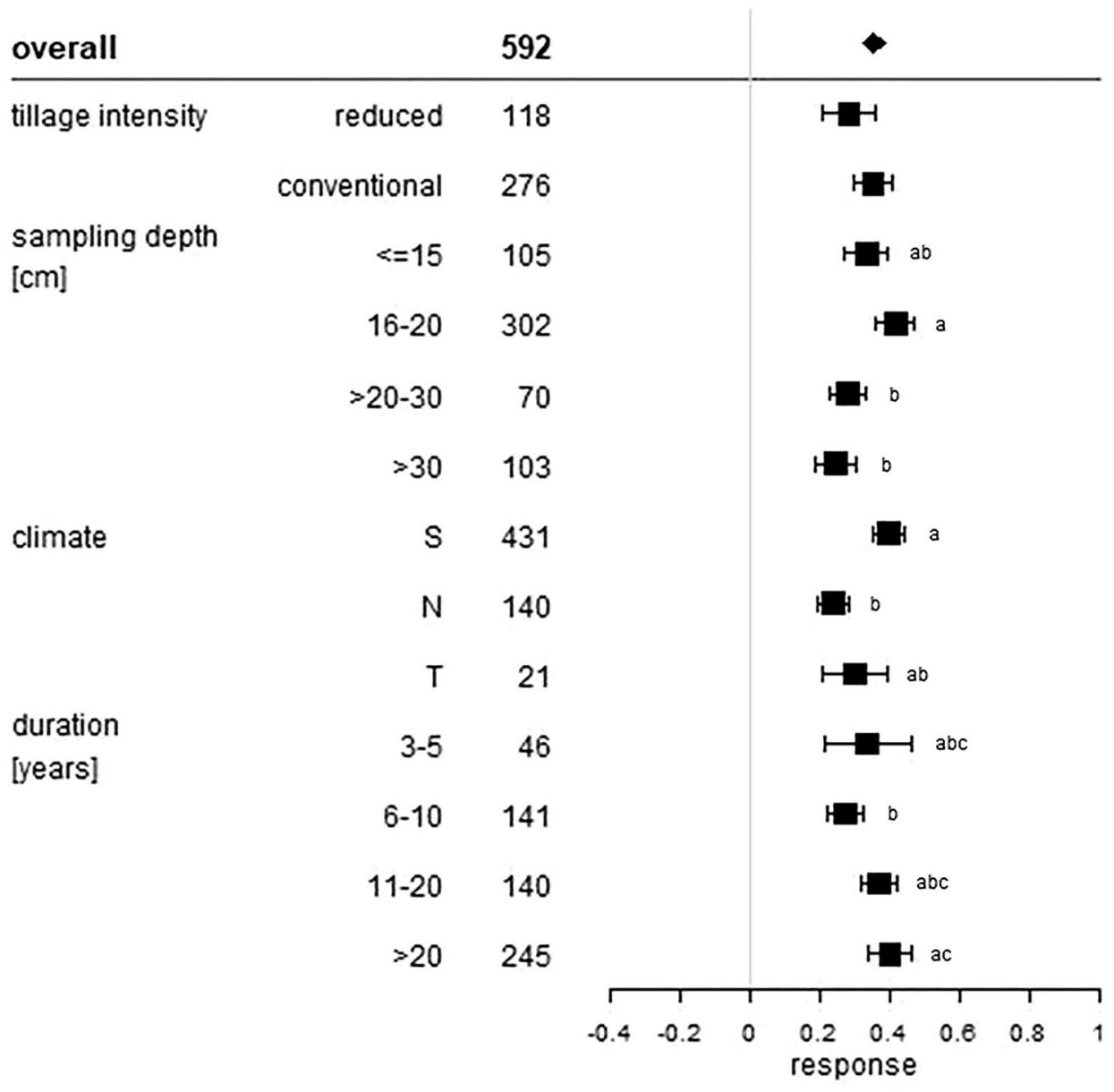

Figure 1. Relative response of manure applications on soil organic carbon stocks influenced by tillage intensity, sampling depth $(\mathrm{cm})$, climate and duration (years) of the considered treatments. The overall grand mean of all individual treatments is presented in the first row followed by the considered subcategories below. Each response ratio is presented as the range between the upper and lower $95 \%$ confidence intervals. Points within the range represent the mean response ratio. The range between both confidence intervals of the grand mean is shown by the extent of the rectangle. The number in each treatment row represents the number of pairwise comparisons on which the statistic is based. The grey line was drawn at response ratio $=0$. Different letters in each subcategory indicate statistical significant differences.

results in an increased net primary production of plants and increased yields $s^{26-28}$. Increasing plant primary production leads to an increase of crop residue inputs and rhizodeposition, which both enhance SOC sequestration ${ }^{29}$.

Tillage intensity effect. Out of 592 treatments that we analyzed, 394 treatments provided information on tillage intensity. 276 treatments were conducted on soils under conventional tillage and 118 treatments on reduced tillage soils. The relative SOC change of the tillage intensity group is presented in Fig. 1 . Both treatments showed positive magnitudes with a mean increase of SOC stocks of $35 \%$ for conventional tillage and $28 \%$ for reduced tillage systems. $\triangle \mathrm{SOC}$ was $10.7 \mathrm{Mg} \mathrm{ha}^{-1}$ for conventional tillage and $8.5 \mathrm{Mg} \mathrm{ha}^{-1}$ in reduced tillage systems (Fig. 2). It is known that reduced tillage has beneficial effects on soil quality, e.g. physical, biological and chemical properties ${ }^{30-32}$, but the effects of tillage on carbon accumulation are controversially discussed. While many studies showed higher SOC accumulation in reduced tillage systems after manure application ${ }^{33-35}$, Baker et al. ${ }^{36}$ argued that SOC accumulation caused by reduced tillage are biased, as most of the studies conducted only involved shallow sampling. Studies which involved deeper sampling often show no positive or insignificant sequestration effects ${ }^{36}$. Our results point to different dynamics. The intercategorical evaluation of tillage intensity and sampling depth shows that manure applications even under reduced tillage led to the smallest but still a significant enrichment of SOC in depths $>30 \mathrm{~cm}$ (Supplementary Material, Figure S1 and S2). $\Delta S O C$ increased by 3.7 $\mathrm{Mg} \mathrm{ha}^{-1}$ corresponding to an $\mathrm{R}$ of $19 \%$. Conventional tillage in depths $>30 \mathrm{~cm}$ led to a SOC increase of $23 \%$ corresponding to $5.6 \mathrm{Mg} \mathrm{ha}^{-1}$. Shallow sampling depths $\leq 15 \mathrm{~cm}$ led to a SOC increase of $21 \%$ under reduced tillage and a $\triangle S O C$ of $7.2 \mathrm{Mg} \mathrm{ha}^{-1}$. Under conventional tillage, shallow sampling depths showed a larger SOC increase of $40 \%$ and also a larger $\triangle \mathrm{SOC}$ of $9.0 \mathrm{Mg} \mathrm{ha}^{-1}$. Overall, sampling depth-wise both tillage intensities showed the same SOC increase with large relative and absolute SOC increases in shallow soil depths and smaller 


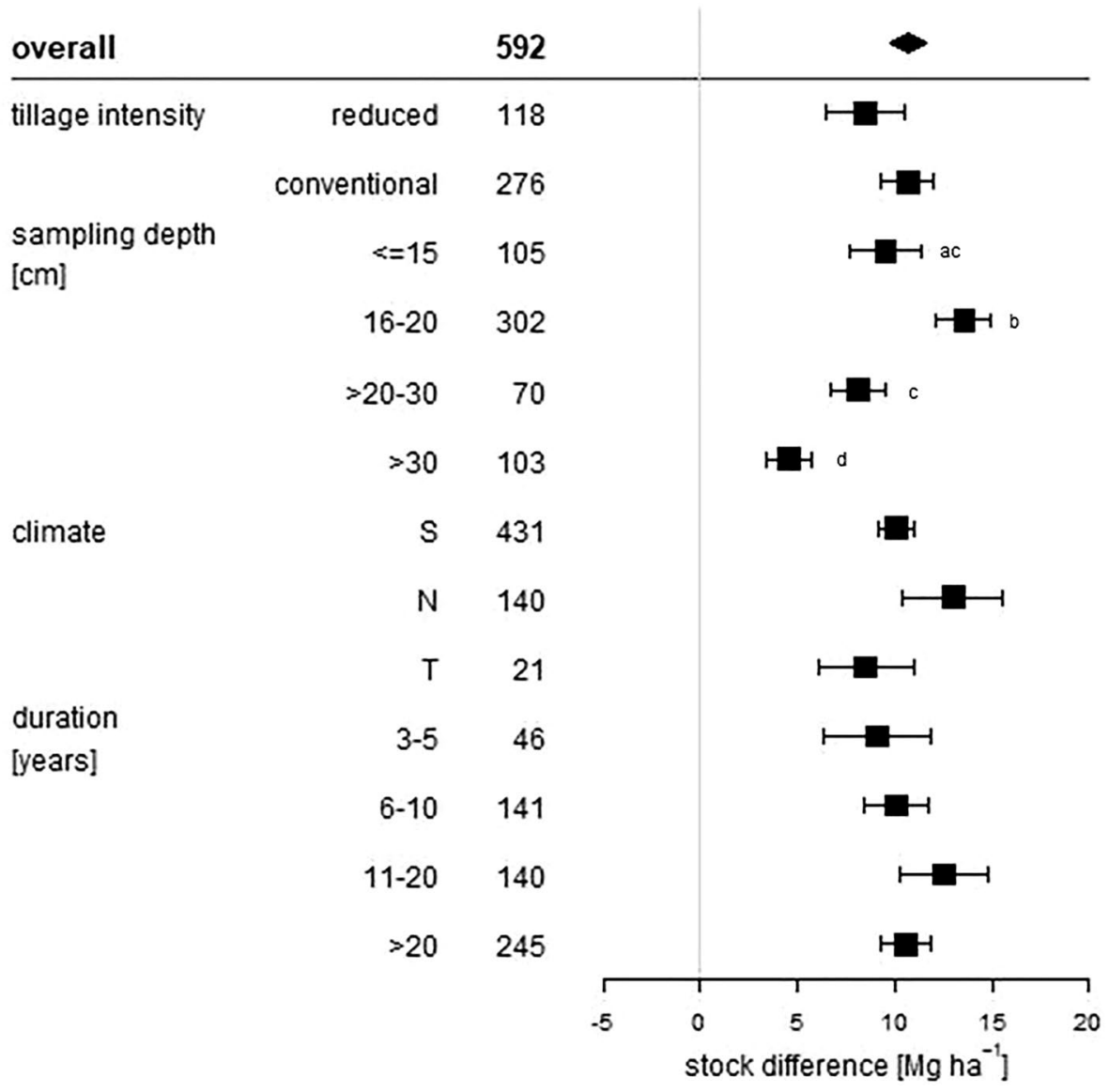

Figure 2. Absolute response $\left(\mathrm{Mg} \mathrm{ha}^{-1}\right)$ of manure applications on soil organic carbon stocks influenced by tillage intensity, sampling depth $(\mathrm{cm})$, climate and duration (years) of the considered treatments. The overall grand mean of all individual treatments is presented in the first row followed by the considered subcategories below. Each response is presented as range between the upper and lower $95 \%$ confidence intervals. Points within the range represent the mean response. The range between both $95 \%$ confidence intervals of the grand mean is shown by the extent of the rectangle. The number in each treatment row represents the number of pairwise comparisons on which the statistic is based. The grey line was drawn at stock difference $=0 \mathrm{Mg} \mathrm{ha}^{-1}$. Different letters in each subcategory indicate statistical significant differences.

responses in deeper regions. This seems logical, as manure applications under conventional tillage are usually only ploughed into the soil up to a depth of $20-30 \mathrm{~cm}$, or in the case of reduced tillage only very shallowly or not at all.

Regarding sampling depth, a 12\% lower SOC stock response was observed at near-surface sampling depth equal to or less than $15 \mathrm{~cm}$, compared to $16-20 \mathrm{~cm}$ soil depth (Fig. 1). If sampling depth was $>20-30 \mathrm{~cm}$, SOC stock increased by $28 \%$. In $>30 \mathrm{~cm}$ soil depth, SOC increased by $24 \%$. $\Delta$ SOC showed higher results in nearsurface regions than in greater soil depth, with $9.5 \mathrm{Mg} \mathrm{ha}^{-1}$ in the first $15 \mathrm{~cm}$ and $4.6 \mathrm{Mg} \mathrm{ha}^{-1}$ in depths $>30 \mathrm{~cm}$ (Fig. 2). The largest $\Delta S O C$ was achieved in $16-20 \mathrm{~cm}$ soil depth with $13.6 \mathrm{Mg} \mathrm{ha}^{-1}$. The vertical distribution of SOC in agriculturally used soils can differ largely, depending on the applied tillage practice ${ }^{37}$. Where SOC accumulates in the soil surface in reduced- or no tillage systems, ploughing in conventional systems can lead to a shift of SOC in deeper soil regions ${ }^{38}$. However, our results showed no significant differences in $\triangle S O C$ in shallow regions of conventional tillage soils compared to reduced tillage soils. Conventionally tilled soils showed a larger relative response, but again this difference was not significant. This result corresponds to findings of a meta-analysis of cover crop induced SOC effects, where also no significant differences between SOC stocks of conventional and reduced tillage soils could be identified ${ }^{10}$.

Climate effect. Figure 1 presents the relative SOC stock change induced by climatic conditions. The lowest response ratio was observed in non-tropical climates, with an average SOC stock increase of $24 \%$. SOC stock changes in tropical climates had a positive mean value of $30 \%$. The highest positive response, with an average of $40 \%$, was accounted for sub-tropical climates. Tropical climate responses showed a large range and were not significantly different from the other climatic categories due to the low number of only 21 treatments. $\Delta S O C$ showed different dynamics. The highest difference of $12.8 \mathrm{Mg} \mathrm{ha}^{-1}$ was reached under non-tropical climatic conditions (Fig. 2). Subtropical and tropical conditions led to lower $\Delta \mathrm{SOC}$ of $10.1 \mathrm{Mg} \mathrm{ha} \mathrm{g}^{-1}$ and $8.5 \mathrm{Mg} \mathrm{ha}^{-1}$, 
respectively. The relative and absolute SOC changes confirms common paradigm. Generally, soils in cool and humid climates have a larger potential to store SOC than soils in dry and warm regions, due to lower decomposition rates and, therefore, higher carbon accumulation ${ }^{9}$. Also Maillard and Angers ${ }^{14}$ showed that the absolute difference in SOC stocks after manure application is lower in tropical and warm regions than in cool regions ${ }^{14}$. The response ratio results can be explained by initial SOC content and stocks in tropical and sub-tropical soils, which are generally lower than in soils of cooler regions ${ }^{9}$. SOC-poor soils have a larger potential to store additional SOC than SOC-rich soils and, therefore, have higher initial SOC accumulation rates ${ }^{39}$. This leads to a larger relative SOC increase in sub-tropical and tropical soils, compared to SOC-richer soils in non-tropical regions. Our results of the intercategorical grouping of the climate categories and initial SOC partly confirm this understanding (Supplementary Material, Figure S3 and S4). Out of 263 treatments under subtropical conditions, which reported initial SOC values, 160 reported an initial SOC content $<1 \%$. These treatments showed a large response ratio of $48 \%$ but low $\triangle \mathrm{SOC}$ results of $10.3 \mathrm{Mg} \mathrm{ha}^{-1}$. In turn, most of the treatments under non-tropical conditions which reported SOC, showed an initial SOC content $>2 \%$. These treatments were characterized by a low mean response ratio of $23 \%$ but a high SOC stock difference of $28 \mathrm{Mg} \mathrm{ha}^{-1}$. Due to low number of samples $(n=23)$, the error bar is wide and limits a conclusive statement. The analysis under tropical conditions was only possible for intermediate initial SOC contents due to the small number of samples.

Temporal effect. The relative SOC stock response connected with the durations of the experiments are shown in Fig. 1. Four different durations were analyzed. The relative mean stock increase of treatments with durations between 3 and 5 years was 34\%. If experiments had durations between 6 and 10 years, SOC stocks increased by $27 \%$. Between 11 and 20 years, mean response ratio was $36 \%$. For durations higher than 20 years, SOC stocks changed by $40 \%$. The highest stock difference was gained between 11 and 20 years and $>20$ years, with a $\triangle S O C$ of 12.5 and $10.6 \mathrm{Mg} \mathrm{ha}^{-1}$ (Fig. 2). If the duration was between 3 and 5 years, stocks only changed by $9.1 \mathrm{Mg} \mathrm{ha}^{-1}$, but showed a high relative gain. This is not surprising, as initial SOC accumulation rates are generally high if the area is feasible and management practices are of good choice ${ }^{7}$. As there is no large difference in the effect sizes (relatively and absolutely) between durations between 3 and 5 years and more than 20 years, SOC stocks do not change systematically with time, if applied manure amounts did not differ interannually. This finding indicates the potential of manure to store carbon in the long term. But, as SOC stocks do not increase with duration, carbon saturation is indicated. The timing of saturation not only depends on soil and input material properties, but also on the initial SOC content. Soils with high initial SOC content reach carbon saturation within a short period of time, whereas soils with low initial SOC need more time ${ }^{40}$. West and Six showed that carbon saturation might occur over a period of 26 years under conventional rotation and 21 years under no $\mathrm{till}^{39}$. Moreover, the saturation equilibrium seem to depend on the soil texture, sandy soils being more prone to $\mathrm{C}$ saturation ${ }^{41}$. According to Wiesmeier et al., finer textured soils showed a depletion of $\mathrm{SOC}^{42}$. Due to the variety of different factors influencing SOC saturation, we further analyzed the intercategorical effect of the initial SOC content, soil texture and tillage intensity on the temporal SOC storage dynamics.

Our findings regarding the influence of initial SOC on carbon saturation supports the common paradigm. Treatments with low initial SOC show large relative responses in all durations and no depletion over time in absolute terms (Supplementary Material, Figure S5). Treatments with intermediate initial SOC showed lower relative responses and a depletion of $\triangle S O C$ between durations between 11 and 20 years and durations $>20$ years (Supplementary Material, Figure S6).

With regard to the tillage intensity, the experiment duration does not seem to play a major role. All response ratios show wide ranges and quite similar mean values but slight increases regarding long experimental duration $>20$ years with 32\% under reduced and $40 \%$ under conventional tillage (Supplementary Material, Figure S7). The $\triangle$ SOC results also do not allow a meaningful conclusion (Supplementary Material, Figure S8). Error bars are too wide and mean values are too similar. However, a slight depletion is indicated under conventional tillage at durations $>20$ years. Here, the $\triangle$ SOC showed a lower response of $9.3 \mathrm{Mg} \mathrm{ha}^{-1}$.

Texture-wise the situation is different. Mean response ratios were high in sandy soils with experimental duration between 11 and 20 years and $>20$ years with $56 \%$ and $40 \%$ respectively (Supplementary Material, Figure S9). However, with respect to SOC stocks, both analyzed durations did not differ largely and showed a low level (Supplementary Material, Figure S10). Fine textured clay soils however, showed both high relative and absolute mean responses in large durations with $74 \%$ and $21.3 \mathrm{Mg} \mathrm{ha}^{-1}$ in durations between 11 and 20 years. Our results therefore seem to contradict the statement that clay soils show SOC depletions over time. But a more conclusive statement requires more long-term experiments with durations $>20$ years.

Soil properties effect. The influence of initial SOC content on the relative effect size within our analysis is presented in Fig. 3. Treatments with low initial SOC content $<1 \%(46 \%)$ showed higher stock increases than treatments with initial SOC content between 1 and $2 \%$, with stock increases of $25 \%$. Treatments with initial SOC content $>2 \%$ resulted in a mean response of $37 \%$. $\triangle$ SOC results were highest in treatments with initial SOC $>2 \%$ $\left(21.5 \mathrm{Mg} \mathrm{ha}^{-1}\right)$ and were lower with decreasing initial SOC content with $12.4 \mathrm{Mg} \mathrm{ha}^{-1}$ in treatments with $1-2 \%$ initial SOC and $9.8 \mathrm{Mg} \mathrm{ha}^{-1}$ in treatments with initial SOC $<1 \%$ (Fig. 4). This finding is not unexpected as even small relative SOC stock changes in soils with high SOC content are leading to large absolute stock differences. In turn, large relative changes in soils with a low initial SOC are leading to a low absolute difference. Soils with an intermediate initial SOC showed an intermediate absolute stock difference. The relative effect of intermediate initial SOC content was the lowest of all responses but the difference was not significant compared to high initial SOC content.

All soil texture classes had positive significant responses on SOC stocks after manure was applied, but responses differed largely between the texture classes (Fig. 3). There are different processes related to soil carbon 


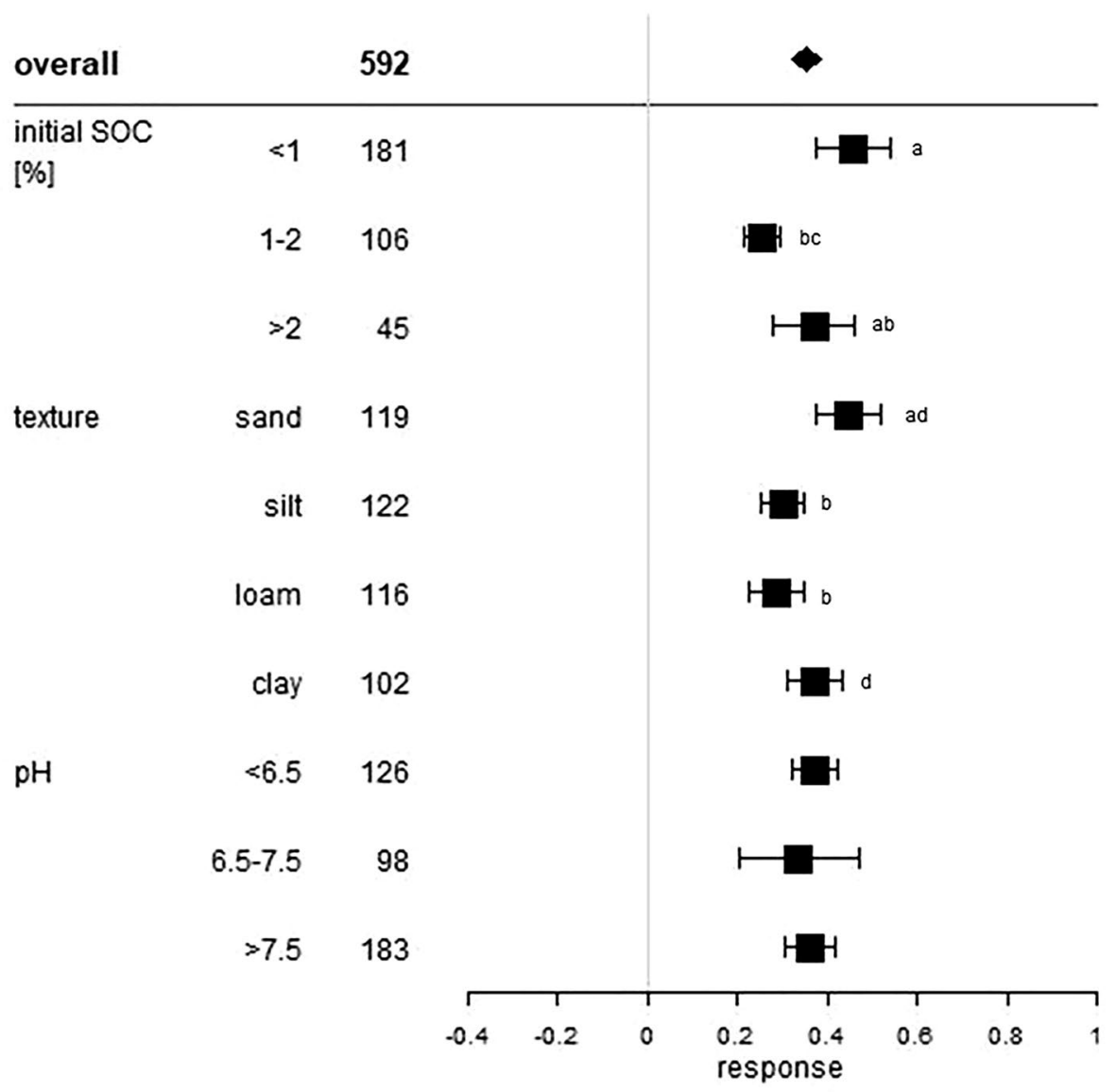

Figure 3. Relative response of manure applications on soil organic carbon stocks influenced by the initial soil organic carbon content (\%), soil texture and soil $\mathrm{pH}$ value of the considered treatments. The overall grand mean of all individual treatments is presented in the first row followed by the considered subcategories below. Each response ratio is presented as the range between the upper and lower $95 \%$ confidence intervals. Points within the range represent the mean response ratio. The range between both $95 \%$ confidence intervals of the grand mean is shown by the extent of the rectangle. The number in each treatment row represents the number of pairwise comparisons on which the statistic is based. The grey line was drawn at response ratio $=0$. Different letters in each subcategory indicate statistical significant differences.

stabilization as a function of soil texture. These processes often depend on the soil clay content. Sorption processes of SOC on soil mineral surfaces and SOC incorporation within soil aggregates can both be enhanced by higher content of clay-sized particles, as clay-sized particles have a higher reactive surface area than coarser particles ${ }^{43}$. This supports our findings that texture classes with higher clay content showed significantly increased $\Delta S O C$ in loam and clay soils with mean differences of 11.7 and $11.3 \mathrm{Mg} \mathrm{ha}^{-1}$ (Fig. 4). Furthermore, clay soils also showed high relative SOC increases (37\%), suggesting that soils with small particle sizes are best suited for SOC storage. Due to the lower specific surface area, sandy soils tend to have higher leaching losses of dissolved organic carbon than finer soil material and are usually more aerated, which favors SOC decomposition. Both processes underpin our finding concerning manure application on sandy soils. Results showed a high relative increase of $45 \%$ but the lowest of all analyzed absolute SOC responses with $8.2 \mathrm{Mg} \mathrm{ha}^{-1}$. The high relative increase seems to be related to low initial SOC values, which in our evaluation often occurred in sandy soils $(n=51)$ (Supplementary Material, Figure S11 and S12). Out of all initial SOC value classes, only the $<1 \%$ class could be evaluated because higher initial values occurred too rarely $(\mathrm{n}<10)$.

Soils with $\mathrm{pH}<6.5$ showed a mean response of $37 \%$ and a mean SOC increase of $13.1 \mathrm{Mg} \mathrm{ha}^{-1}$. Neutral soils (6.5-7.5) had a mean SOC increase of $7.9 \mathrm{Mg} \mathrm{ha}^{-1}$ corresponding to $25 \%$, while alkaline soils (>7.5) showed a SOC increase of $7.9 \mathrm{Mg} \mathrm{ha}^{-1}$ corresponding to $36 \%$ (Figs. 3, 4). The supply of protons to soils, from atmospheric or organic sources, influences several biological and chemical processes e.g. soil microbial activity, which affects decomposition of organic matter and carbon sequestration ${ }^{44}$. Generally, increasing soil $\mathrm{pH}$ stimulates microbial activity and decomposition rates of fresh organic matter and, therefore, favors SOC mineralization ${ }^{45}$. However, it is still unknown whether a higher net primary production as a consequence of raising soil pH (e.g. through lime application) and, therefore, higher plant residue and root biomass inputs could possibly offset higher soil respiration and promote carbon sequestration in the long term ${ }^{46,47}$. Furthermore, a higher amount of $\mathrm{Ca}^{2+}$ ions could favor formation of mineral-organic complexes in soils with higher $\mathrm{pH}$. Decreasing $\mathrm{pH}$ values, in turn, can reduce 


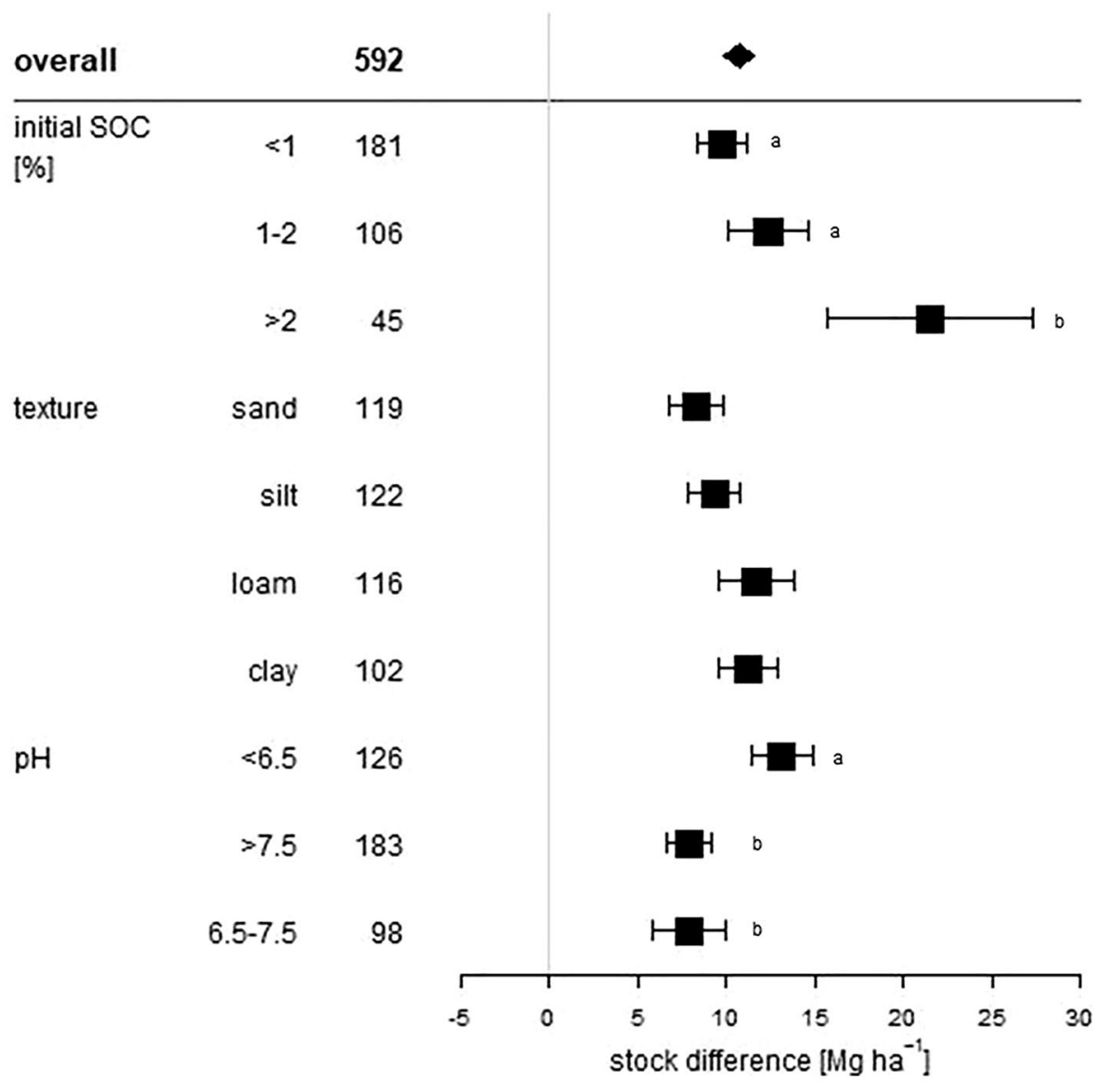

Figure 4. Absolute response $\left(\mathrm{Mg} \mathrm{ha}^{-1}\right)$ of manure applications on soil organic carbon stocks influenced by the initial soil organic carbon content (\%), the soil texture and the soil $\mathrm{pH}$ value of the considered treatments. The overall grand mean of all individual treatments is presented in the first row followed by the considered subcategories below. Each response is presented as the range between the upper and lower $95 \%$ confidence intervals. Points within the range represent the mean response. The range between both $95 \%$ confidence intervals of the grand mean is shown by the extent of the rectangle. The number in each treatment row represents the number of pairwise comparisons on which the statistic is based. The grey line was drawn at stock difference $=0 \mathrm{Mg} \mathrm{ha}^{-1}$. Different letters in each subcategory indicate statistical significant differences.

decomposition rates of SOC ${ }^{48}$. Therefore, acidity could possibly promote SOC accumulation which our results confirmed as manure application showed the highest absolute and relative SOC stock responses in acid soils.

Fertilizer properties and amount effect. In total, 16 different manure types from different origins (including farmyard manure, i.e. various excretions originating from agricultural activity) were categorized of which seven were a combination of single manure types, which occurred in a low number and therefore were difficult to evaluate individually. The application of each manure type had a significantly positive response on SOC stocks (Figs. 5, 6). The lowest effects came from the application of green manure, straw, and combined applications of both with $17 \%$ and $5.1 \mathrm{Mg} \mathrm{ha}^{-1}, 23 \%$ and $6.4 \mathrm{Mg} \mathrm{ha}^{-1}$ and $11 \%$ corresponding to $4.5 \mathrm{Mg} \mathrm{ha}^{-1}$, respectively. In contrast, pig manure, cattle manure and farmyard manure led to the highest responses with $50 \%$ and $15.8 \mathrm{Mg} \mathrm{ha}^{-1}, 32 \%$ and $15 \mathrm{Mg} \mathrm{ha}^{-1}$ and $41 \%$ corresponding to $9.7 \mathrm{Mg} \mathrm{ha}^{-1}$, respectively. Other livestock excretions, namely poultry manure, sheep manure and horse manure responded with $39 \%$ and $8.9 \mathrm{Mg} \mathrm{ha}^{-1}$, $35 \%$ and $7 \mathrm{Mg} \mathrm{ha}^{-1}$ and $23 \%$ corresponding to $8.3 \mathrm{Mg} \mathrm{ha}^{-1}$, respectively, and thus also showed good SOC storage performances. Maillard and Angers ${ }^{14}$ found a comparable result with cattle manure, inducing high SOC stock differences, but they only considered three livestock species (cattle, pig, poultry) and they included only a small number of treatments, which led to a high variability. Liu et al. ${ }^{40}$ found an SOC response ratio of $12.8 \%$ after straw application on paddy and upland soils. This result corroborates our findings. Out of all manure types, pig manure showed the highest carbon accumulation potential. However, all manure types showed positive responses, especially those of livestock.

The effect of SOC stock changes influenced by additional added mineral fertilizer are presented in Figs. 5 and 6. If mineral fertilizer was added, the SOC stocks increased significantly by $40 \%$ and absolutely by $11.9 \mathrm{Mg} \mathrm{ha}^{-1}$. Treatments with no additional mineral fertilizer raised SOC stocks by $30 \%$. Here, the absolute difference was slightly lower, with 10.2 $\mathrm{Mg} \mathrm{ha}^{-1}$ (Fig. 6). As already explained in "General effect", additional mineral fertilizer 
overall

manure type

cumulated amount

$[\mathrm{Mg} / \mathrm{ha}]$

annualy amount

$[\mathrm{Mg} / \mathrm{ha}]$

NPK

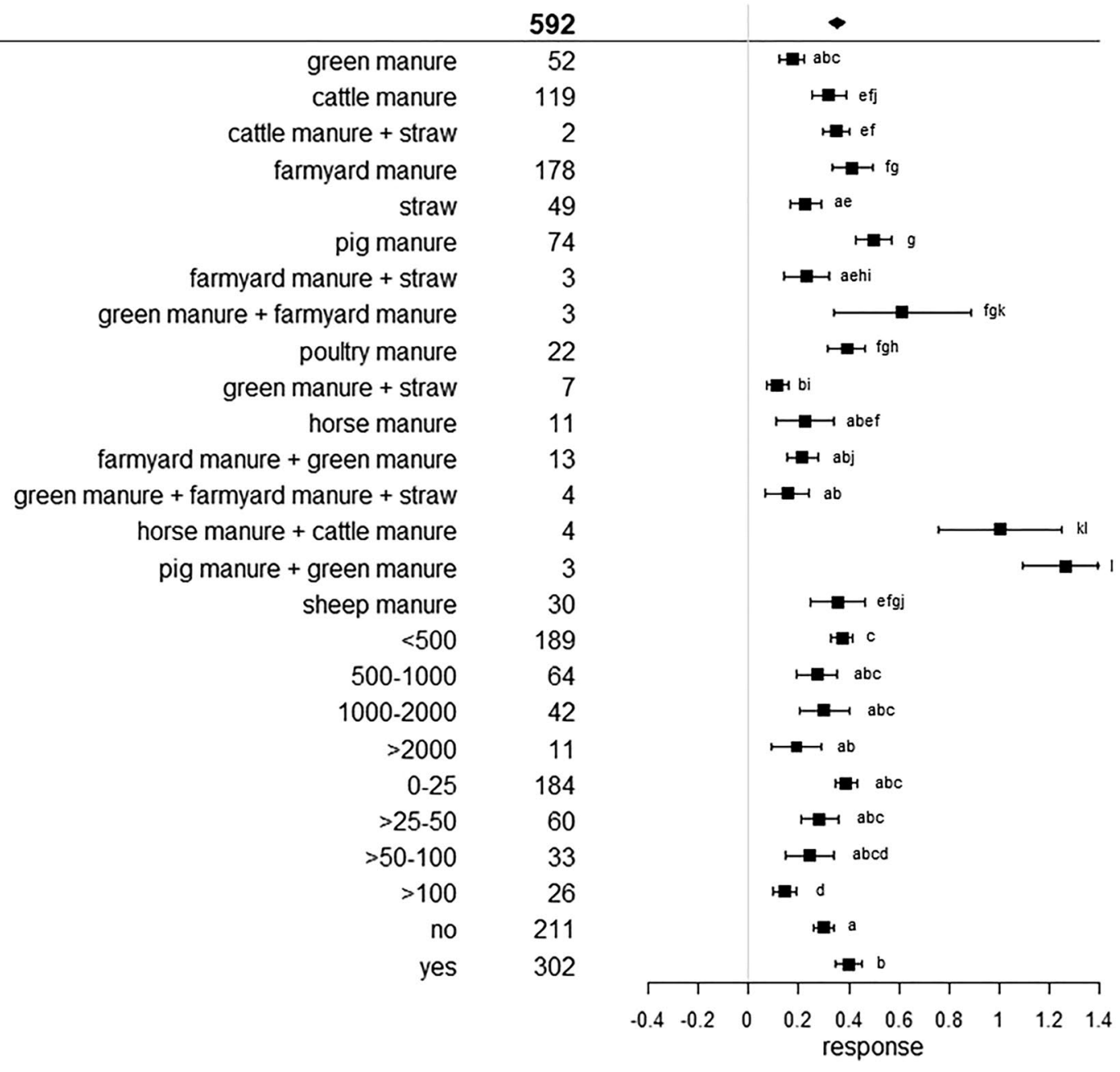

Figure 5. Relative response of manure applications on SOC stocks influenced by manure type, annual manure amount $\left(\mathrm{Mg} \mathrm{ha}^{-1}\right)$, the accumulated manure amount $\left(\mathrm{Mg} \mathrm{ha}^{-1}\right)$, and additionally added chemical fertilizer (NPK) of the considered treatments. The overall grand mean of all individual treatments is presented in the first row followed by the considered subcategories below. Each response ratio is presented as the range between the upper and lower 95\% confidence intervals. Points within the range represent the mean response ratio. The range between both $95 \%$ confidence intervals of the grand mean is shown by the extent of the rectangle. The number in each treatment row represents the number of pairwise comparisons on which the statistic is based. The grey line was drawn at response ratio $=0$. Different letters in each subcategory indicate statistical significant differences.

input provides a delivery of nutrients. Plant growth is promoted, aboveground and belowground. This enhanced net primary production with higher biomass inputs explains higher SOC stocks, as rising biomass yields generally correlate with rising SOC values. Although aboveground biomass is removed after harvest, increased root growth and higher crop residue amounts have a positive effect on SOC content, compared to unfertilized treatments, especially if manure and mineral fertilizer application is combined ${ }^{49-51}$. Further, also the relative SOC gain was higher if additional mineral fertilizer was used. Initial SOC values could be the explanation. The intercategorical evaluation of NPK and initial SOC values identified the most NPK treatments with low initial SOC values and high response ratios of 54\% (Supplementary Material, Figure S13). Treatments with low initial SOC were also the majority in the non-NPK grouping, but many treatments with high SOC levels were also found. Here, response ratios only hardly differed from each other. $\triangle$ SOC showed the same dynamics for both NPK and nonNPK treatments with higher stock differences in soils (Supplementary Material, Figure S14).

SOC stock responses induced by different amounts of manure application are presented in Figs. 5 and 6. Cumulative and annual manure amounts, each in four different quantities were analyzed. Amounts $<500 \mathrm{Mg} \mathrm{ha}^{-1}$, the lowest cumulative quantity, showed the highest relative SOC stock response, which was $38 \%$, but had a low absolute SOC gain, with $9.2 \mathrm{Mg} \mathrm{ha}^{-1}$ (Figs. 5, 6). The amounts ranging between 500 and $1000 \mathrm{Mg} \mathrm{ha}^{-1}$ showed a response ratio of $27 \%$ and a stock difference of $10.1 \mathrm{Mg} \mathrm{ha}^{-1}$. Between 1000 and $2000 \mathrm{Mg} \mathrm{ha}^{-1}$ the response was $30 \%$ relatively and $13.5 \mathrm{Mg} \mathrm{ha}^{-1}$ absolutely. The last and highest amount range classified was $>2000 \mathrm{Mg} \mathrm{ha}^{-1}$ with a response ratio of $19 \%$ and a $29.7 \mathrm{Mg} \mathrm{ha}^{-1}$ SOC stock change, which is the highest absolute value. Annual amount results showed a similar dynamic. Low annual manure amounts of $0-25 \mathrm{Mg} \mathrm{ha}^{-1} \mathrm{a}^{-1}$ resulted in a low $\Delta \mathrm{SOC}$ of $9.6 \mathrm{Mg} \mathrm{ha}^{-1}$ but a high relative change of $39 \%$. High annual amounts $>100 \mathrm{Mg} \mathrm{ha}^{-1} \mathrm{a}^{-1}$, however showed 
overall

manure type

cumulated amount

[Mg/ha]

annualy amount

[Mg/ha]

NPK

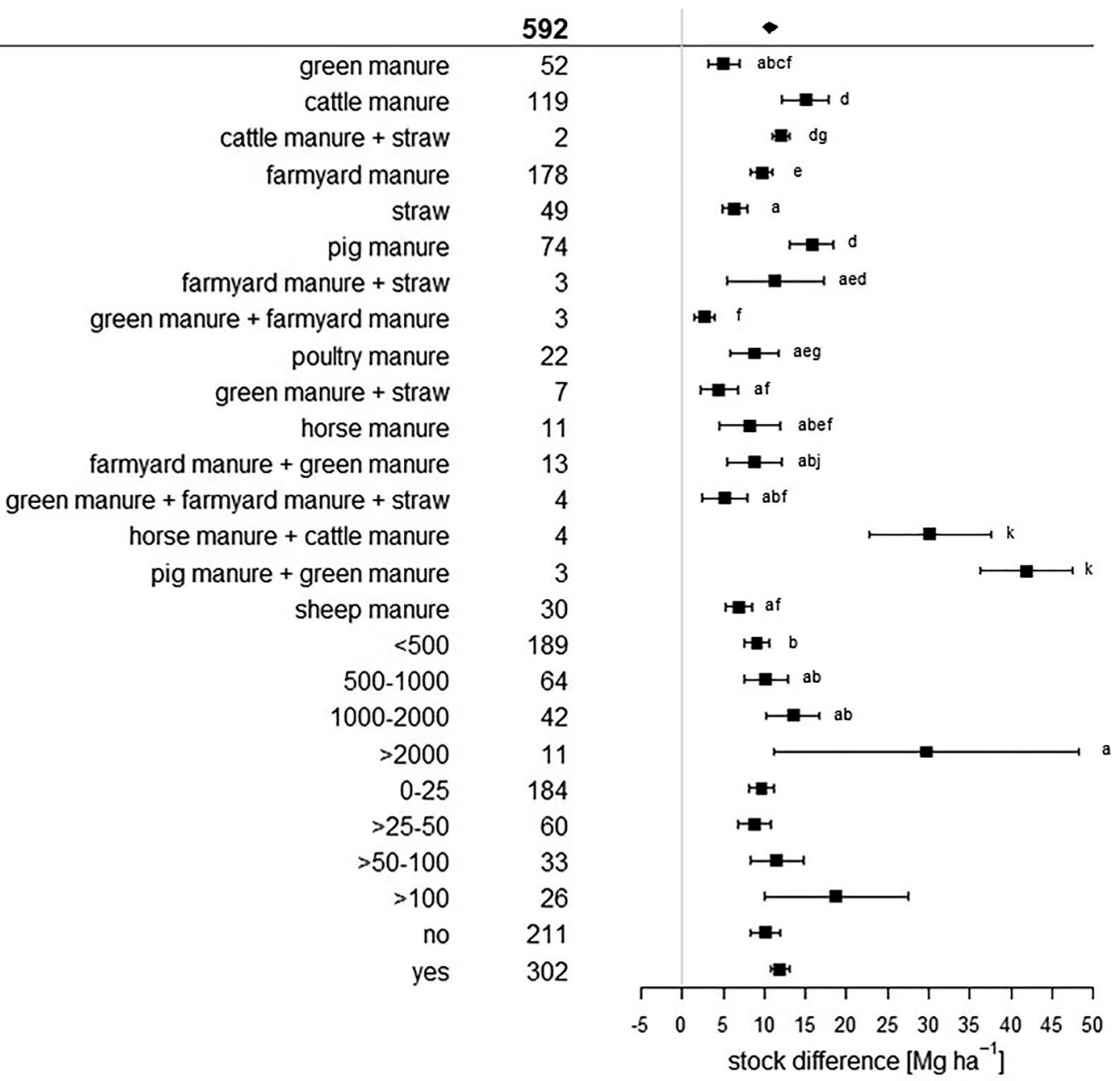

Figure 6. Absolute response $\left(\mathrm{Mg} \mathrm{ha}^{-1}\right)$ of manure applications on soil organic carbon stocks influenced by the manure type, the annual manure amount $\left(\mathrm{Mg} \mathrm{ha}^{-1}\right)$ the accumulated manure amount $\left(\mathrm{Mg} \mathrm{ha}^{-1}\right)$ and additional added chemical fertilizer (NPK) of the considered treatments. The overall grand mean of all individual treatments is presented in the first row followed by the considered subcategories below. Each response is presented as the range between the upper and lower $95 \%$ confidence interval. Points within the range represent the mean response. The range between both $95 \%$ confidence intervals of the grand mean is shown by the extent of the rectangle. The number in each treatment row represents the number of pairwise comparisons on which the statistic is based. The grey line was drawn at stock difference $=0 \mathrm{Mg} \mathrm{ha}^{-1}$. Different letters in each subcategory indicate statistical significant differences.

a high $\triangle \mathrm{SOC}$ of $18.8 \mathrm{Mg} \mathrm{ha}^{-1}$ but a lower response ratio of $14 \%$. The relative change in SOC stocks does not increase with higher annual input amounts. Rather, the response ratio reached the highest relative change at the lowest annual and cumulative input amount. However, our results indicate that high input amounts seem to be connected with high SOC stock differences. A regression analysis of the connection between the input amount and $\triangle S O C$ indicated a significant linear, but weak relationship for both annual $\left(\mathrm{p}=4.1 \mathrm{e}-11 ; \mathrm{R}^{2}=0.13\right)$ (Fig. 7a) and cumulative quantities $\left(\mathrm{p}=1.6 \mathrm{e}-07 ; \mathrm{R}^{2}=0.087\right)$ (Fig. 7b). Maillard and Angers ${ }^{14}$ also found a linear relationship between cumulative carbon input and SOC stock difference up to very high levels of carbon inputs which support our finding. To further evaluate this relationship, we analyzed the link between $\Delta$ SOC and annual manure inputs as a function of the subcategories we investigated. The regression plots are located in the Supplementary Material, Figure S15a-t. A Shapiro-Wilk test, which was carried out in advance, showed a non-normal distribution of the data. Regarding tillage intensity effects, no significant relationship could be found for reduced tillage treatments (Supplementary Material, Figure S15a), whereas conventional tillage treatments showed a linear relationship between annual amounts and $\Delta S O C\left(p<2.2 e-16 ; R^{2}=0.5\right)$ (Supplementary Material, Figure S15b). Differences between soil texture groups could not be identified. All texture classes showed no significant relationships (Supplementary Material, Figure S15c-f). In the climate subcategories (Supplementary Material, Figure S15g,h), a significant relationship was only identified under non-tropical conditions $\left(R^{2}=0.24\right.$; $\mathrm{p}=0.0019$ ) (Supplementary Material, Figure S15g). Applications under tropical conditions were not included in the regression analysis due to the low number of treatments. Considering the various sampling depths (Supplementary Material, Figure S15i-1) only depths between 16 and $20 \mathrm{~cm}$ showed significance $\left(\mathrm{R}^{2}=0.34 ; \mathrm{p}=3.1 \mathrm{e}-13\right)$ (Supplementary Material, Figure S15j). Regarding soil pH conditions (Supplementary Material, Figure S15m-o), 

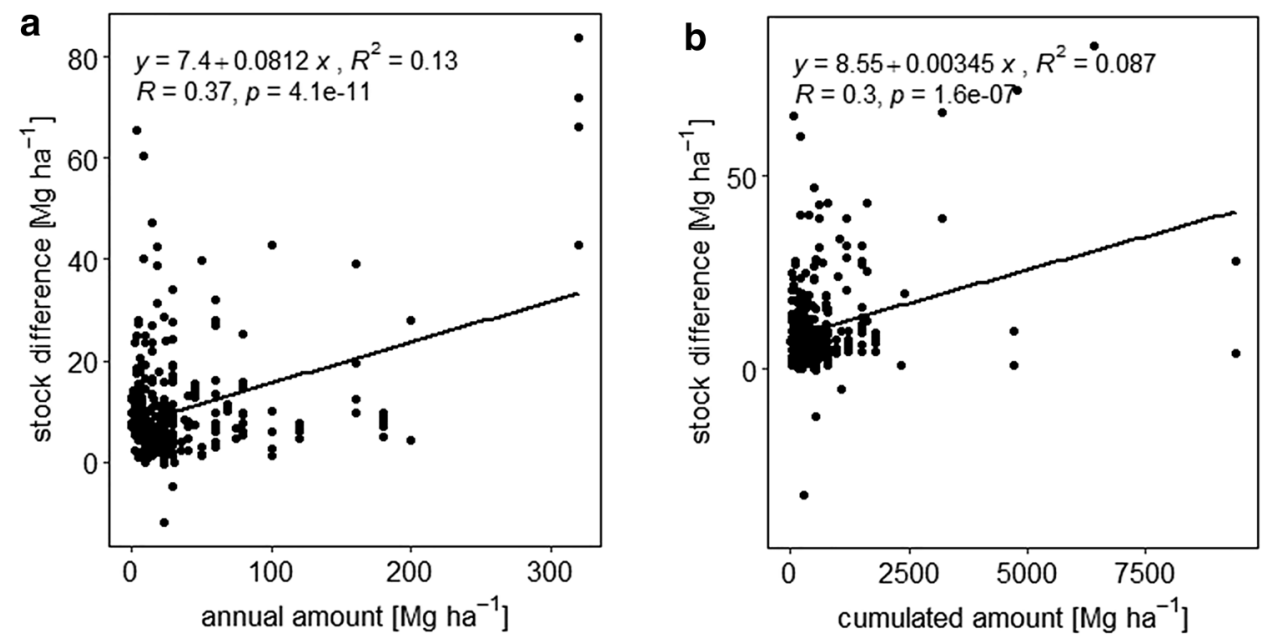

Figure 7. Relationship between the SOC stock difference $\left(\mathrm{Mg} \mathrm{ha}^{-1}\right)$ and cumulative manure-C input $\left(\mathrm{Mg} \mathrm{ha}^{-1}\right)$ (a) and the SOC stock difference $\left(\mathrm{Mg} \mathrm{ha}^{-1}\right)$ and annual manure input $\left(\mathrm{Mg} \mathrm{ha}^{-1}\right)(\mathbf{b}) \cdot \mathrm{R}^{2}$ represents the coefficient of determination.

a significant linear increase was identified in $\mathrm{pH}$ neutral soils but $\left(\mathrm{R}^{2}=0.2 ; \mathrm{p}=9.9 \mathrm{e}-5\right)$ (Supplementary Material, Figure S15o), whereas acidic soils showed a significant linear decrease $\left(R^{2}=0.1 ; p=0.044\right)$ (Supplementary Material, Figure S15m). Low initial SOC $<1 \%\left(R^{2}=0.037 ; p=0.049\right)$ (Supplementary Material, Figure S15p) and high initial SOC $>2 \%\left(R^{2}=0.57 ; p=1.6 e-6\right)$ (Supplementary Material, Figure S15r) showed significant positive relationships. The application of additional mineral fertilizers led to an insignificant relation (Supplementary Material, Figure S15s) whereas non-NPK treatments showed a significant positive link (Supplementary Material, Figure S15t) $\left(\mathrm{R}^{2}=0.41 ; \mathrm{p}=7.8 \mathrm{e}-15\right)$. To summarize, the annual amount of application seems to be important only under conventional tillage, non-tropical climate conditions and $\mathrm{pH}$-neutral as well as SOC-rich or SOCdepleted soils and only if no additional mineral fertilization is applied. Under other conditions, there seems to be no statistically significant relation between $\triangle \mathrm{SOC}$ and annual manure amounts.

\section{Conclusions}

Globally, manure applications induced a raise of SOC stocks. However, our results indicate that the increase effect is linked to many factors and can show large differences. These factors included management decisions (tillage intensity, manure amount, duration of application), site properties (climate, initial SOC content, soil texture) and manure characteristics (manure origin and the combined application with synthetic fertilizer). To better understand carbon dynamics, more long-term SOC field data are required, especially the factors influencing carbon saturation need to be further investigated. Moreover, many measurements under tropical conditions need to be conducted because the small number of treatments found made it impossible to draw definitive conclusions. Additional to that, more holistic approaches within carbon dynamics assessment methods need to be established. For example, although, conventional tillage and synthetic fertilization have high effects in terms of SOC enrichment, positive aspects through reduced tillage and external effects (e.g. through the production of synthetic fertilizers) should play a role in the development of sustainable management strategies. Expanding the scope will help to avoid misleading conclusions.

Received: 2 May 2020; Accepted: 20 January 2021

Published online: 09 March 2021

\section{References}

1. Schimel, D. et al. Radiative forcing of climate change. Climate Change 1995: The Science of Climate Change, 65-131 (1996).

2. IPCC ed. Climate Change 2007. Mitigation of Climate Change: Contribution of Working Group III to the Fourth Assessment Report of the Intergovernmental Panel on Climate Change (Cambridge University Press, Cambridge, 2007).

3. Mazzoldi, A., Hill, T. \& Colls, J. J. Assessing the risk for CO2 transportation within CCS projects, CFD modelling. Int. J. Greenh. Gas Control 5, 816-825 (2011).

4. Wallquist, L., Seigo, S. L., Visschers, V. H. M. \& Siegrist, M. Public acceptance of CCS system elements. A conjoint measurement. Int. J. Greenh. Gas Control 6, 77-83 (2012).

5. Lehmann, J. \& Kleber, M. The contentious nature of soil organic matter. Nature 528, 60 (2015).

6. Glaser, B. \& Birk, J. J. State of the scientific knowledge on properties and genesis of Anthropogenic Dark Earths in Central Amazonia (terra preta de Índio). Geochim. Cosmochim. Acta 82, 39-51. https://doi.org/10.1016/j.gca.2010.11.029 (2012).

7. Minasny, B. et al. Soil carbon 4 per mille. Geoderma 292, 59-86. https://doi.org/10.1016/j.geoderma.2017.01.002 (2017).

8. Baldock, J. \& Skjemstad, J. O. Soil organic carbon/soil organic matter. (Keine Angabe) (1999).

9. Lal, R. Soil carbon sequestration impacts on global climate change and food security. Science (New York, N. Y.) 304, $1623-1627$. https://doi.org/10.1126/science.1097396 (2004). 
10. Poeplau, C. \& Don, A. Carbon sequestration in agricultural soils via cultivation of cover crops-a meta-analysis. Agr. Ecosyst. Environ. 200, 33-41 (2015).

11. Bolinder, M. A. et al. The effect of crop residues, cover crops, manures and nitrogen fertilization on soil organic carbon changes in agroecosystems. A synthesis of reviews. Mitig. Adapt. Strateg. Glob. Change 168, 25. https://doi.org/10.1007/s11027-020-09916 $-3(2020)$.

12. Zhang, B. et al. Global manure nitrogen production and application in cropland during 1860-2014. A 5 arcmin gridded global dataset for Earth system modeling. Earth Syst. Sci. Data 9, 667-678. https://doi.org/10.5194/essd-9-667-2017 (2017).

13. Han, P., Zhang, W., Wang, G., Sun, W. \& Huang, Y. Changes in soil organic carbon in croplands subjected to fertilizer management. A global meta-analysis. Sci. Rep. 6, 27199. https://doi.org/10.1038/srep27199 (2016).

14. Maillard, É. \& Angers, D. A. Animal manure application and soil organic carbon stocks. A meta-analysis. Glob. Change Biol. 20, 666-679. https://doi.org/10.1111/gcb.12438 (2014).

15. FAO. Measuring and Modelling Soil Carbon Stocks and Stock Changes in Livestock Production Systems. Guidelines for Assessment. Livestock Environmental Assessment and Performance (LEAP) Partnershi (Rome, Italy, 2018).

16. Men, M.-X., Peng, Z.-P., Hao, X. \& Yu, Z.-R. Investigation on Pedotransfer function for estimating soil bulk density in Hebei province. Chin. J. Soil Sci. 1, 20 (2008).

17. Bernoux, M., Cerri, C., Arrouays, D., Jolivet, C. \& Volkoff, B. Bulk densities of Brazilian Amazon soils related to other soil properties. Soil Sci. Soc. Am. J. 62, 743-749 (1998).

18. La, M. \& Jones, C. A. Bulk density of soils in relation to soil physical and chemical properties. Soil Sci. Soc. Am. J. 55, 476-481 (1991).

19. Gattinger, A. et al. Enhanced top soil carbon stocks under organic farming. Proc. Natl. Acad. Sci. 109, 18226-18231 (2012).

20. Liu, L. \& Greaver, T. L. A global perspective on belowground carbon dynamics under nitrogen enrichment. Ecol. Lett. 13, 819-828 (2010).

21. Hedges, L. V., Gurevitch, J. \& Curtis, P. S. The meta-analysis of response ratios in experimental ecology. Ecology 80, 1150-1156 (1999).

22. Guo, L. B. \& Gifford, R. M. Soil carbon stocks and land use change. A meta analysis. Glob. Change Biol. 8, 345-360 (2002).

23. Johnson, D. W. \& Curtis, P. S. Effects of forest management on soil C and N storage. Meta analysis. Forest Ecol. Manag. 140, 227-238 (2001).

24. Qin, W., Hu, C. \& Oenema, O. Soil mulching significantly enhances yields and water and nitrogen use efficiencies of maize and wheat. A meta-analysis. Sci. Rep. 5, 16210 (2015).

25. R Core Team. R: A Language and Environment for Statistical Computing (R Foundation for Statistical Computing, Vienna, 2018).

26. Cai, A. et al. Soil fertility and crop yield after manure addition to acidic soils in South China. Nutr. Cycl. Agroecosyst. 111, 61-72. https://doi.org/10.1007/s10705-018-9918-6 (2018).

27. Du, Y., Cui, B., Wang, Z., Sun, J. \& Niu, W. Effects of manure fertilizer on crop yield and soil properties in China. A meta-analysis. CATENA 193, 104617 (2020).

28. Obour, A., Stahlman, P. \& Thompson, C. Long-term residual effects of feedlot manure application on crop yield and soil surface chemistry. J. Plant Nutr. 40, 427-438 (2017).

29. Stewart, C. E., Paustian, K., Conant, R. T., Plante, A. F. \& Six, J. Soil carbon saturation. Concept, evidence and evaluation. Biogeochemistry 86, 19-31. https://doi.org/10.1007/s10533-007-9140-0 (2007).

30. Liebig, M., Tanaka, D. \& Wienhold, B. Tillage and cropping effects on soil quality indicators in the northern Great Plains. Soil Tillage Res. 78, 131-141. https://doi.org/10.1016/j.still.2004.02.002 (2004).

31. Rasmussen, K. J. Impact of ploughless soil tillage on yield and soil quality. A Scandinavian review. Soil Tillage Res. 53, 3-14. https ://doi.org/10.1016/S0167-1987(99)00072-0 (1999).

32. Willekens, K., Vandecasteele, B., Buchan, D. \& de Neve, S. Soil quality is positively affected by reduced tillage and compost in an intensive vegetable cropping system. Appl. Soil Ecol. 82, 61-71. https://doi.org/10.1016/j.apsoil.2014.05.009 (2014).

33. Yaduvanshi, N. \& Sharma, D. R. Tillage and residual organic manures/chemical amendment effects on soil organic matter and yield of wheat under sodic water irrigation. Soil Tillage Res. 98, 11-16. https://doi.org/10.1016/j.still.2007.09.010 (2008).

34. Mando, A. et al. Long-term effects of fallow, tillage and manure application on soil organic matter and nitrogen fractions and on sorghum yield under Sudano-Sahelian conditions. Soil Use Manag. 21, 25-31. https://doi.org/10.1079/SUM2005287 (2005).

35. Bogužas, V. et al. Long-term effect of tillage systems, straw and green manure combinations on soil organic matter. Zemdirbyste Agric. 102, 243-250. https://doi.org/10.13080/z-a.2015.102.031 (2015).

36. Baker, J. M., Ochsner, T. E., Venterea, R. T. \& Griffis, T. J. Tillage and soil carbon sequestration-what do we really know?. Agric. Ecosyst. Environ. 118, 1-5. https://doi.org/10.1016/j.agee.2006.05.014 (2007).

37. Angers, D. A. \& Eriksen-Hamel, N. S. Full-inversion tillage and organic carbon distribution in soil profiles. A meta-analysis. Soil Sci. Soc. Am. J. 72, 1370. https://doi.org/10.2136/sssaj2007.0342 (2008).

38. Piccoli, I. et al. Disentangling the effects of conservation agriculture practices on the vertical distribution of soil organic carbon. Evidence of poor carbon sequestration in North-Eastern Italy. Agric. Ecosyst. Environ. 230, 68-78 (2016).

39. West, T. O. \& Six, J. Considering the influence of sequestration duration and carbon saturation on estimates of soil carbon capacity. Clim. Change 80, 25-41. https://doi.org/10.1007/s10584-006-9173-8 (2007).

40. Liu, C., Lu, M., Cui, J., Li, B. \& Fang, C. Effects of straw carbon input on carbon dynamics in agricultural soils. A meta-analysis. Glob. Change Biol. 20, 1366-1381. https://doi.org/10.1111/gcb.12517 (2014).

41. Angers, D. A., Arrouays, D., Saby, N. P. \& Walter, C. Estimating and mapping the carbon saturation deficit of French agricultural topsoils. Soil Use Manag. 27, 448-452 (2011).

42. Wiesmeier, M. et al. Carbon sequestration potential of soils in southeast Germany derived from stable soil organic carbon saturation. Glob. Change Biol. 20, 653-665. https://doi.org/10.1111/gcb.12384 (2014).

43. Dungait, J. A., Berhe, A. A., Gregory, A. S. \& Hopkins, D. W. In Soil and Climate. Series: Advances in Soil Science (eds Lal, R. \& Stewart, B. A.) 171-182 (CRC Press, Boca Raton, 2018).

44. Paul, E. A. Soil microbiology, Ecology and Biochemistry (Elsevier, San Diego, 2015).

45. Andersson, S. \& Nilsson, S. I. Influence of $\mathrm{pH}$ and temperature on microbial activity, substrate availability of soil-solution bacteria and leaching of dissolved organic carbon in a mor humus. Soil Biol. Biochem. 33, 1181-1191 (2001).

46. Paradelo, R., Virto, I. \& Chenu, C. Net effect of liming on soil organic carbon stocks. A review. Agric. Ecosyst. Environ. 202, 98-107. https://doi.org/10.1016/j.agee.2015.01.005 (2015).

47. Holland, J. E. et al. Liming impacts on soils, crops and biodiversity in the UK. A review. Sci. Total Environ. 610-611, 316-332. https://doi.org/10.1016/j.scitotenv.2017.08.020 (2018).

48. Motavalli, P. P., Palm, C. A., Parton, W. J., Elliott, E. T. \& Frey, S. D. Soil pH and organic C dynamics in tropical forest soils. Evidence from laboratory and simulation studies. Soil Biol. Biochem. 27, 1589-1599 (1995).

49. Manna, M., Swarup, A., Wanjari, R., Mishra, B. \& Shahi, D. Long-term fertilization, manure and liming effects on soil organic matter and crop yields. Soil Tillage Res. 94, 397-409. https://doi.org/10.1016/j.still.2006.08.013 (2007).

50. Li, Z., Liu, M., Wu, X., Han, F. \& Zhang, T. Effects of long-term chemical fertilization and organic amendments on dynamics of soil organic $\mathrm{C}$ and total $\mathrm{N}$ in paddy soil derived from barren land in subtropical China. Soil Tillage Res. 106, 268-274. https://doi. org/10.1016/j.still.2009.12.008 (2010). 
51. Yu, H., Ding, W., Luo, J., Geng, R. \& Cai, Z. Long-term application of organic manure and mineral fertilizers on aggregation and aggregate-associated carbon in a sandy loam soil. Soil Tillage Res. 124, 170-177. https://doi.org/10.1016/j.still.2012.06.011 (2012).

\section{Acknowledgements}

We thank Lukas Albrecht who helped preparing the figures. We thank Saskia Furman and Jamie Bowcock who gave comments on a draft version of the manuscript.

\section{Author contributions}

A.G. wrote the main manuscript text and prepared figures. B.G. revised the manuscript.

\section{Funding}

Open Access funding enabled and organized by Projekt DEAL.

\section{Competing interests}

The authors declare no competing interests.

\section{Additional information}

Supplementary Information The online version contains supplementary material available at https://doi. org/10.1038/s41598-021-82739-7.

Correspondence and requests for materials should be addressed to B.G.

Reprints and permissions information is available at www.nature.com/reprints.

Publisher's note Springer Nature remains neutral with regard to jurisdictional claims in published maps and institutional affiliations.

(c) (i) Open Access This article is licensed under a Creative Commons Attribution 4.0 International License, which permits use, sharing, adaptation, distribution and reproduction in any medium or format, as long as you give appropriate credit to the original author(s) and the source, provide a link to the Creative Commons licence, and indicate if changes were made. The images or other third party material in this article are included in the article's Creative Commons licence, unless indicated otherwise in a credit line to the material. If material is not included in the article's Creative Commons licence and your intended use is not permitted by statutory regulation or exceeds the permitted use, you will need to obtain permission directly from the copyright holder. To view a copy of this licence, visit http://creativecommons.org/licenses/by/4.0/.

(C) The Author(s) 2021 